\title{
Six volcanologists killed in Colombian eruption
}

London. In an ironic twist of fate, six scientists are believed to have died in a volcanic eruption in Colombia last week as they worked on a monitoring system to help predict future eruptions and thus save lives. Among those killed on the 14,000-foot Galeras volcano was Geoffrey Brown, professor of Earth sciences at Britain's Open University and a pioneer in the use of gravity measurements to help increase the accuracy of predictions about when and where a volcano is likely to erupt.

Galeras has historically been the most

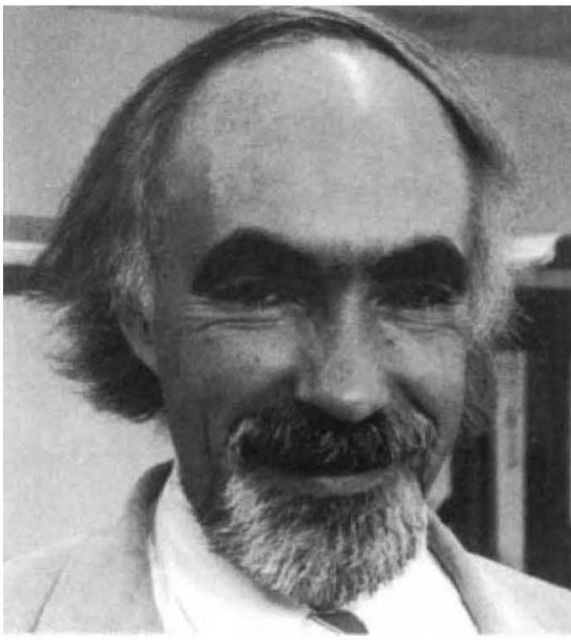

Eruption killed Geoffrey Brown.

active volcano in Colombia, erupting 21 times since 1580 . It has been under close observation by scientists since first indications of renewed activity in 1988. A small eruption in May 1989 was followed by another in October 1991, and then by a more violent explosion last July, which destroyed the lava dome.

Such precursors of a major eruption (a tilting of the dome was observed in November), together with the fact that it is located only $8 \mathrm{~km}$ from the centre of the town of Pasto, made Galeras one of seven volcanoes singled out for special attention under the United Nations International Decade of Natural Disaster Reduction.

The scientists who died were taking pari in a workshop organized by Colombian, Canadian and US scientists. One of the main goals of the workshop was to develop a strategic plan for monitoring the volcano's present activity and interpreting its geological past.

Part of the workshop involved a daylong field trip on 14 January to the active crater to collect gas samples and make other observations. According to reports received from Colombia, it was during this visit that

two eruptions occurred about two hours apart. The first, which trapped those in the crater, lasted about 15 minutes.

Among those injured by the eruption was the main organizer of the workshop, Stan Williams of Arizona State University, who has been studying the volcano for several years. $\mathrm{He}$ is said to have been pulled to safety from 30 metres down in the crater by a Colombian geologist from the National Institute for Geological and Mineral Investigations and a driver on the expedition. Williams was subsequently flown back to the United States for medical treatment.

Other scientists who had moved further into the crater, including Brown, were all killed. At the time of the eruption, several of them were installing equipment to monitor gases escaping from the dome.

Brown was setting up equipment to measure the gravitational field in the dome. Small changes can result from shifts in the magma within a volcano. In previous studies in Costa Rica and Europe, Brown and his colleagues have shown that such changes may provide clues to eruptions not provided by seismic data or measurements of surface distortion. "It was a type of reconnaissance exercise to see if we could set up a gravity monitoring network", says Hazel Rymer, who has worked closely with Brown in developing the techniques.

Although information is still scanty, a spokesman for the British Foreign Office said earlier this week that nine bodies had been recovered and that three more people were still unaccounted for. The dead scientists were mostly from Colombia, but also included an unidentified researcher from the Institute of Volcanology in Russia.

This week, colleagues at the Open Uni-

\section{EPA makes small field tests easier}

Washington. In an attempt to clear the decks before the new administration takes office, the US Environmental Protection Agency (EPA) last week issued its long-awaited rule on small-scale field testing of microbial pesticides.

Under the new rule, EPA, which regulates the use and distribution of pesticides under the Federal Insecticide, Fungicide and Rodenticide Act, will require prior notification of small-scale field testing in the environment for only a small subset of microbial pesticides - those posing the greatest potential risks or where there is insufficient information about the potential risk of

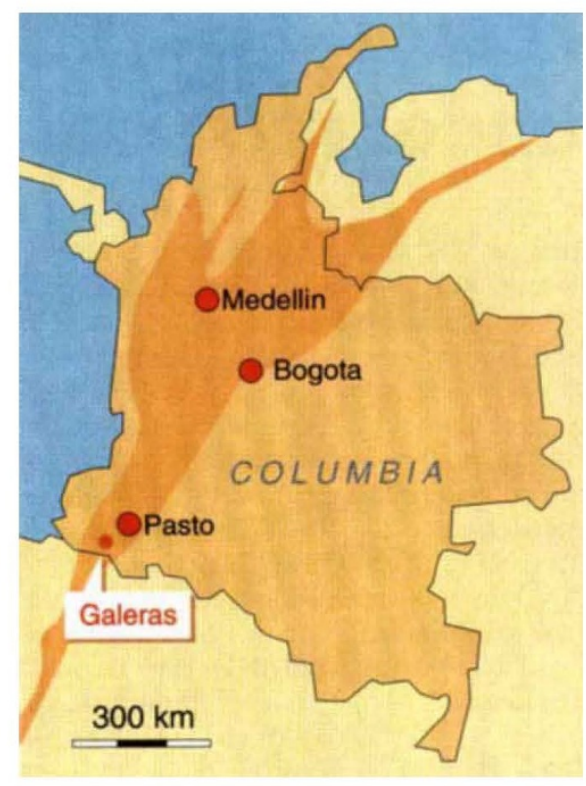

The Galeras volcano is near the border with Ecuador in southwestern Colombia.

versity paid tribute both to Brown's work for the Earth sciences department and to his activity as head of the university's research committee. In the latter position, he had been responsible for coordinating the university's participation in the recent research evaluation exercise carried out by the Universities Funding Council.

"Geoff passionately believed that good teaching should be supported by good research", said Chris Wilson, acting head of the department. "His role was crucial in the research selectivity exercise, and also in the way that research in the department has flourished."

Early next month, the department is opening a new laboratory wing, described by Wilson as a "crowning achievement" to Brown's work for the university. The building has been partly funded by the Wolfson Foundation and will be the first specifically built for research purposes on the Open University campus.

David Dickson

introduction into the environment. Notification is now required for all genetically altered and nonindigenous microbial pesticides. The new rule applies only to smallscale field tests. Companies carrying out field tests of more than 10 acres will still be required to apply routinely for experimental use permits from EPA.

The new proposal was welcomed by the Industrial Biotechnology Association, which has worked closely with the Bush administration for more than two years to clarify the scope of the agency's supervision and reduce the regulatory burden on the industry.

Diane Gershon 